\title{
Study on cadmium accumulation of different tomato rootstocks
}

\author{
Yongmei $\mathrm{Wu}^{1}$, Le Liang ${ }^{2}$, Yongdong $\mathrm{Xie}^{2}$, Yi Tang ${ }^{2}$, and Lei Liu ${ }^{1, *}$ \\ ${ }^{1}$ Chengdu Academy of Agricultural and Forestry Sciences, 611130 Chengdu, Sichuan, China \\ ${ }^{2}$ College of Horticulture, Sichuan Agricultural University, 611130 Chengdu, Sichuan, China
}

\begin{abstract}
To investigate the effects of cadmium $(\mathrm{Cd})$ stress on the growth of different tomato rootstocks, the $\mathrm{Cd}$ content and transport efficient of rootstocks, the pot experiment was carried out with wild eggplant rootstocks Solanum torvum and Totosga, tomato rootstock "Dalishengen", "Banzhen18" and "Guozhen1". Under Cd stress, the plant heights of "Banzhe18" and "Dalishengen" were significantly higher than other; the main root lengths of Totosga and $S$. torvum were significantly longer than other. The dry weight of the "Banzhen18" was the highest, and the "Guozhen1" was the smallest. The order of Cd content in roots was $S$. torvum > Totosga > "Guozhen1" > "Banzhen18" > "Dalishengen"; the content of $\mathrm{Cd}$ in the stem of "Dalishengen" was the highest, and Totosga was the least. The order of Cd content in leaves was "Guozhen1" > "Dalishengen" > "Banzhen18" > Totosga > S. torvum. S. torvum had the smallest translocation factor, and "Dalishengen" had the biggest. Cd stress showed significant inter-specific differences in rootstock growth and $\mathrm{Cd}$ content. The plant height of tomato rootstock was significantly higher than the wild eggplant rootstock, and the main root length of wild eggplant rootstock was significantly longer than tomato rootstock. The Cd contents in S. torvum and Totosga mainly accumulated in the roots, so the $\mathrm{Cd}$ content in the aerial part was much lower than other.
\end{abstract}

\section{Introduction}

Heavy metals have atomic density greater than $4 \mathrm{~g} / \mathrm{cm}^{3}$ or 5 times, or more, than the density of water $\left(1 \mathrm{gm} / \mathrm{cm}^{3}\right)$ and include around 38 elements [1]. The concentrations of several heavy metals [cadmium (Cd), chromium, copper, nickel and lead] in plants exceed the limit values [2]. One of these heavy metals, $\mathrm{Cd}$ pollution in soil mainly comes from transportation, agricultural inputs, sewage irrigation and sludge fertilization [3]. When Cd accumulates in a certain concentration in plants, plant growth will be inhibited, including growth retardation and yield decline; moreover, different crops have different sensitivity to $\mathrm{Cd}$ [4]. $\mathrm{Cd}$ is one of the most dangerous metals to biological systems, being a matter of concern to farmers and health organizations find that $\mathrm{Cd}$ can potentially transfer hazardous levels to dangerous human health through food chain [5].

Many ways have been aimed to reduce $\mathrm{Cd}$ accumulation in plants grown on $\mathrm{Cd}$ contaminated land: increasing soil $\mathrm{pH}$, using adsorbents and keeping fields flooded long time [6-7]. But the cost and environmental have limited the widespread use these methods. Grafting can regulate heavy metal accumulation in the edible parts of crops, and can be widely use. Many studies have demonstrated that grafting can reduce the accumulation of heavy metals in the scion of crops, such as grafting can reduce the heavy metal uptake of Cyphomandra betacea, its seedlings are grafted onto three different rootstocks (eggplant, Solanum nigrum, and tomato) and planted in Cd-contaminated soil [8]. The grafting technique is applied to eggplant (Solanum melongena) and tomato (Lycopersicon esculentum) plants using Solanum torvum as rootstock grafting on $\mathrm{Cd}$ accumulation in shoots, demonstrated that grafting can decreasing the $\mathrm{Cd}$ content of shoots but there are other mechanisms that interact with grafting to reduce $\mathrm{Cd}$ content [9].

In the actual production process, grafting has been applied to all aspects of vegetables: resistance to pests and diseases, overcoming continuous cropping obstacles, resistance to various stresses, etc. Rootstocks are the basis of the entire grafted plant: absorption of nutrients, providing strong support, etc., so the choice of rootstocks is vital to meet the demand for production while meeting the demand for production. Therefore, this experiment studied the growth of different rootstocks under the same $\mathrm{Cd}$ conditions, the content of $\mathrm{Cd}$ in different rootstocks and the transport efficient, which provided an experimental basis for the $\mathrm{Cd}$ tolerance test of tomato and Solanaceae.

\section{Materials and methods}

\subsection{Materials}

Wild eggplant rootstocks $S$. torvum and Totosga, tomato rootstock "Dalishengen", "Banzhen18" and "Guozhen1" tomato were purchased at Chengdu Seed Station. 
The germination time and growth habits of several different rootstocks were different, it was necessary to carry out germination and seedling rising according to the characteristics of different rootstocks, so as to ensure the consistency of rootstock seedlings. Totosga and $S$. torvum as wild eggplants, it took a long time to germination under suitable conditions, "Guozhen1", "Banzhen18" and " Dalishengen" as tomato the germination time was relatively short, so the Totosga and S. torvum were germinated firstly, and after 15-18 days, "Guozhen1", "Banzhen18" and " Dalishengen " were carried out. Then seeding after the seeds were white, sowing with 50-hole trays (2-3 capsules per well), then waited for the rootstock seedlings to grow 2 to 3 true leaves and then transplanted them into the soil treated with $\mathrm{Cd}$, choose seedlings of the same growth were transplanted, 6 plants were transplanted per pot, and 3 replicates were set. Referring to the test method of Tang et al. [10], the soil was taken from the paddy field near Sichuan Agricultural University, and the soil was thoroughly air-dried. After air drying, the soil was firstly crushed and then passed through a sieve of $5 \mathrm{~mm}$ and loaded into a plastic vat of $40 \mathrm{~cm}$ in height and $30 \mathrm{~cm}$ in diameter, ensure that the net weight of soil of each pot was $20 \mathrm{~kg}$, then add the appropriate analytical pure $\mathrm{CdCl}_{2} \cdot 2.5 \mathrm{H}_{2} \mathrm{O}$ solution to make the soil $\mathrm{Cd}$ concentration reach $10 \mathrm{mg} / \mathrm{kg}$. After the $\mathrm{Cd}$ solution was added, add distilled water to ensure the soil moisture content in the barrel reaches $80 \%$. Set to balance for 4 weeks to use.

When the rootstock was transplanted for 1 month after normal growth, the most abundant and representative functional leaves were collected. The functional leaves were located in the upper part of the plant, and the size was kept consistent with each treatment. After the collection completed, the plants were stored in $-80{ }^{\circ} \mathrm{C}$ ultra-low temperature refrigerator. After the leaves were collected, the whole rootstocks were harvested together. All the plants were placed in a bucket filled with water. When the soil was soft, carefully removed the roots from the soil to maintain the integrity of the roots, and washing the whole rootstock with deionized water and drying it for use.

\subsection{Experimental Design}

The whole plant was wished with deionized water, the absorbent paper was blotted dry, the main root length and plant height were measured with a ruler, and the fresh weight of roots, stems and leaves was weighed by an electronic balance, and then dried in an oven at $105{ }^{\circ} \mathrm{C}$ for $15 \mathrm{~min}$, dried at $70{ }^{\circ} \mathrm{C}$, measuring its dry weight. The roots, stems and leaves were baked to constant weight, and then ground into powder, roots and stems were passed through a 40 mesh sieve, and the leaves were passed through a 100 mesh sieve, $0.5 \mathrm{~g}$ of sample per treatment scale was placed in a conical flask, and $25 \mathrm{ml}$ of perchloric acid: nitric acid mixture was added in a ratio of 1:4, sealed, and allowed to stand for $12 \mathrm{~h}$. Then boil on the hot plate until the digestive juice was colorless or slightly yellow. After cooling, filter and dilute to $20 \mathrm{ml}$ with deionized water. Determination of $\mathrm{Cd}$ content of test samples by atomic absorption spectrophotometer (Aaanlust 800). The transport efficient refers to the ratio of the metal content in the plant shoot to the metal content in the underground. It was an indicator used to evaluate the ability of plants to transport and enrich heavy metals from root to shoot.

\subsection{Statistic analyses}

Statistical analyses were performed using SPSS 20.0 statistical software (IBM, Chicago, IL, USA).Data were analyzed by Duncan new range method with least significant difference (LSD) at a 5\% confidence level.

\section{Results}

\subsection{Growth of tomato rootstock under $\mathrm{Cd}$ stress}

Table 1. Growth of rootstock, main root length, fresh weight and dry weight under Cd stress

\begin{tabular}{|c|c|c|c|c|}
\hline Cultivar & $\begin{array}{c}\text { Height } \\
(\mathrm{cm})\end{array}$ & $\begin{array}{c}\text { Main root length } \\
(\mathrm{cm})\end{array}$ & $\begin{array}{c}\text { Fresh weight } \\
(\mathrm{g} / \text { plant })\end{array}$ & $\begin{array}{c}\text { Dry weight } \\
(\mathrm{g} / \mathrm{plant})\end{array}$ \\
\hline Banzhen18 & $38.97 \pm 1.76 \mathrm{a}$ & $12.37 \pm 0.15 \mathrm{~b}$ & $13.58 \pm 0.78 \mathrm{a}$ & $1.36 \pm 0.04 \mathrm{a}$ \\
\hline Dlishengen & $38.63 \pm 1.42 \mathrm{a}$ & $12.9 \pm 0.36 \mathrm{~b}$ & $12.1 \pm 0.24 \mathrm{~b}$ & $1.24 \pm 0.02 \mathrm{~b}$ \\
\hline Guozhen 1 & $30.17 \pm 0.15 \mathrm{~b}$ & $11.9 \pm 0.36 \mathrm{~b}$ & $7.11 \pm 0.2 \mathrm{e}$ & $0.67 \pm 0.05 \mathrm{e}$ \\
\hline S. torvum & $17.7 \pm 0.62 \mathrm{c}$ & $27.53 \pm 0.25 \mathrm{a}$ & $8.28 \pm 0.17 \mathrm{~d}$ & $0.83 \pm 0.07 \mathrm{~d}$ \\
\hline Totosga & $18.1 \pm 0.26 \mathrm{c}$ & $28.03 \pm 1.04 \mathrm{a}$ & $10.66 \pm 0.4 \mathrm{c}$ & $1.02 \pm 0.02 \mathrm{c}$ \\
\hline
\end{tabular}

The data in the table is average value \pm standard deviation, different letters in the same precedence indicate significant difference $(P$ $<0.05$ ).

Under different $\mathrm{Cd}$ stress conditions, the growth of different rootstocks was different (Table 1). The "Banzhen18" and "Dalishengen" had the highest plant height, the aerial part grows vigorously, and the plant heights of Totosga and $S$. torvum and the other three kinds of tomato rootstocks. The difference in plant height was larger. The largest "Banzhen18" was 2.20 times the smallest $S$. torvum, the difference was significant $(P<$ $0.05)$, even the smallest "Guozhen1" in the tomato rootstock was 1.67 times the larger of the wild eggplant rootstock Totosga, and the level of difference was significant. In terms of main root length, the difference 
between different rootstocks was opposite to that of plant height. The main root lengths of Totosga and S. torvum were larger than those of the other three kinds of tomato rootstocks, among which $S$. torvum was 2.13 times the "Dalishengen" root, the difference was significant. On fresh weight and dry weight, "Banzhen18" had the largest dry weight, followed by "Dalishengen", but "Guozhen1" had the smallest dry weight, Totosga and $S$. torvum was the fourth and fifth respectively. In summary, the growth characteristics of rootstocks showed significant interspecies differences, in which the plant height of tomato rootstocks grew faster, while the roots of wild eggplant rootstocks grew more vigorously.

\subsection{Cd content of rootstock under $\mathrm{Cd}$ stress}

It can be seen from Table 2 that under $\mathrm{Cd}$ stress conditions, the content of $\mathrm{Cd}$ in the leaves and roots of the rootstock was larger, and the content of $\mathrm{Cd}$ in the stem was smaller. Among them, the $\mathrm{Cd}$ content of the leaves of "Banzhen18", "Hercules" and "Guozhen1" was higher than that of roots, while the Cd content of Totosga and $S$. torvum was smaller than that of roots content. In terms of roots, the order of Cd content was: $S$. torvum $>$
Totosga > Guozhen1 > Banzhen18 > Dalishengen, among them, the largest $S$. torvum had a $\mathrm{Cd}$ content of 7.87 times that of the "Dalishengen", and the Totosga had a $\mathrm{Cd}$ content of 6.27 times that of "Dalishengen". In terms of stems, the $\mathrm{Cd}$ of the "Dalishengen" had the largest, while the Totosga was the smallest, and the rest of the rootstocks were ordered as the Guozhen1 > Banzhen $18>S$. torvum, among them the Cd content of "Dalishengen" was 10.78 times that of Totosga, 6.00 times that of $S$. torvum, and the Cd content of "Banzhen 18 " was 7.88 times of Totosga, which was 4.38 times that of $S$. torvum. In terms of leaves, "Guozhen 1 " had the largest $\mathrm{Cd}$ content, and other rootstocks were ranked as Dalishengen $>$ Banzhen $18>$ Totosga $>S$. torvum. The Cd content of the leaves of "Guozhen1" was 5.08 times of Totosga and 5.73 times of $S$. torvum, the difference was significant $(P<0.05)$. In terms of the transport coefficient, the $S$. torvum was the smallest, the "Dalishengen" was the largest, and it was 25.02 times that of S. torvum. In summary, S. torvum and Totosga, compared with other rootstocks, most of the $\mathrm{Cd}$ content accumulated in the roots, resulting in a much lower $\mathrm{Cd}$ content in the aerial part than other rootstock.

Table 2. Cd content of leaf, stem and root anvil in Cd stress

\begin{tabular}{|c|c|c|c|c|}
\hline Cultivar & $\begin{array}{c}\text { Root } \\
(\mathrm{mg} / \mathrm{kg})\end{array}$ & $\begin{array}{c}\text { Stem } \\
(\mathrm{mg} / \mathrm{kg})\end{array}$ & $\begin{array}{c}\text { Leaf } \\
(\mathrm{mg} / \mathrm{kg})\end{array}$ & $\begin{array}{c}\text { Translocation } \\
\text { factor }\end{array}$ \\
\hline Banzhen18 & $18.28 \pm 0.43 \mathrm{~d}$ & $5.83 \pm 0.29 \mathrm{c}$ & $20.61 \pm 1.94 \mathrm{c}$ & 0.723 \\
\hline Dalishengen & $13.66 \pm 0.79 \mathrm{e}$ & $7.98 \pm 0.14 \mathrm{a}$ & $24.84 \pm 0.43 \mathrm{~b}$ & 1.201 \\
\hline Guozhen1 & $21.86 \pm 1.59 \mathrm{c}$ & $7.39 \pm 0.63 \mathrm{~b}$ & $38.22 \pm 0.59 \mathrm{a}$ & 1.043 \\
\hline Totosga & $85.62 \pm 2.96 \mathrm{~b}$ & $0.74 \pm 0.05 \mathrm{e}$ & $7.52 \pm 0.22 \mathrm{~d}$ & 0.048 \\
\hline S. torvum & $107.5 \pm 2.59 \mathrm{a}$ & $1.33 \pm 0.02 \mathrm{~d}$ & $6.67 \pm 0.65 \mathrm{~d}$ & 0.037 \\
\hline
\end{tabular}

The data in the table is average value \pm standard deviation, different letters in the same precedence indicate significant difference $(P$ $<0.05)$.

\section{Conclusions}

Under Cd stress, the plant heights of "Banzhe18" and "Dalishengen" were significantly higher than other; the main root lengths of Totosga and $S$. torvum were significantly longer than other. The dry weight of the "Banzhen18" was the highest, and the "Guozhen1" was the smallest. The order of Cd content in roots was $S$. torvum > Totosga > "Guozhen1" > "Banzhen18" > "Dalishengen"; the content of $\mathrm{Cd}$ in the stem of "Dalishengen" was the highest, and Totosga was the least. The order of $\mathrm{Cd}$ content in leaves was "Guozhen1" > "Dalishengen" > "Banzhen18" > Totosga $>$ S. torvum. S. torvum had the smallest translocation factor, and "Dalishengen" had the biggest. Cd stress showed significant inter-specific differences in rootstock growth and $\mathrm{Cd}$ content. The plant height of tomato rootstock was significantly higher than the wild eggplant rootstock, and the main root length of wild eggplant rootstock was significantly longer than tomato rootstock. The $\mathrm{Cd}$ content in S. torvum and Totosga mainly accumulated in the roots, so the $\mathrm{Cd}$ contents in the aerial parts were much lower than other.

\section{References}

1. M.Y. Khan, V. Prakash, V. Yada, D.K. Chauhan, S.M. Prasad, Plant Physiol. Biochem. 142, 193-201 (2019)

2. N. Jeelani, Z. Zhua, P. Wang, P. Zhang, S. Song, Aquat. Bot. 147, 92-95 (2017)

3. R. Pang, R. Wang, H. Xie, L. Guo, J. Li, Tianjin Agric. Sci. 22, 87-91 (2016)

4. Y. Yang, Y. Li, Q. Chen, W. Guo, Acta Agric. Boreail- 30,511-517(2015)

5. R. A. Azevedo, P. L. Grata, C. C. Monteiro, R. F. Carvalho. Food Energy Secur. 1,133-140 (2012)

6. I. Cattani, M. Romani, R. Boccell, Agron. Sustain. Dev 28,265-271 (2008) 
7. L. Qian, B. Chen, L. Han. J. Yan, W. Zhang, Environ. Sci. Pollut. Res. 24, 23843-23849(2017)

8. Q. Liu, R. Huo, L. Lin, M. Liao, J. Wang, Int. J. Environ. Anal. Chem. 99, 1247-1254(2019)

9. H. Yuan, L. Sun, P. Tai, W. Liu, X. Li, Sci. Total Environ. 625, 989-995 (2019)

10. F. Tang L. Lin, D. Yang, Chin. J. Soil Sci. 47, 207-212 (2016) 